\title{
Metabarcoding reveals mixed \\ Isochrysidales in marine environments and demonstrates new paleoenvironmental applications for alkenones
}

KAREN WANG AND YONGSONG HUANG

Brown University

Presenting Author: karen_wang@brown.edu

Alkenones are well-established lipid biomarkers synthesized exclusively by algae within the order Isochrysidales. They are a class of $\mathrm{C}_{35-42}$ methyl and ethyl ketones with two to five double bonds. The unsaturation indices of alkenones $\left(\mathrm{U}^{\mathrm{K}}{ }_{37}\right.$ and $\mathrm{U}^{\mathrm{K}}{ }_{37}$ ') are correlated to the water temperature where they were produced and have been used as sea surface temperature proxy since the 1980s. Isochrysidales has been classified into three groups based on 18S rDNA sequencing. In marine settings, Group 3 (marine) Isochrysidales, i.e. Emiliania huxleyi and the closely related Gephyrocapsa oceanica, are often assumed to be the sole alkenone producers in most paleoclimate reconstructions. Later studies implementing DNA sequencing and phylogenetics have revealed Group 1 (freshwater) and Group 2 (brackish) Isochrysidales in lacustrine and estuary environments. Here, through metabarcoding with next-generation sequencing, our studies showed additional Isochrysidales diversity in marine environment as well as new Isochrysidales species. Samples from Chesapeake Bay, U.S.A. and Baltic Sea show that species mixing between Group 1, Group 2 and Group 3 Isochrysidales are common in estuary, marginal seas and fjords. Alkenone contributions from Group 1 and Group 2 Isochrysidlaes increase with decreasing salinity. Samples from Canadian Arctic Archipelago and Arctic Ocean reveal a new lineage of Isochrysidales (Group 2i) widely occurring in sea ice influenced area and produce predominant $\mathrm{C}_{37: 4}$ alkenone. Relative abundance of $\mathrm{C}_{37: 4}$ to total $\mathrm{C}_{37}$ alkenones $\left(\% \mathrm{C}_{37: 4}\right)$ reflects the alkenone contribution from Group $2 \mathrm{i}$ Isochrysidales, and $\% \mathrm{C}_{37: 4}$ in seawater filtered particulate organic matter and surface sediments is significantly correlated with annual mean sea ice concentrations. Downcore sediments spanning the past 14 kyrs in the Svalbard region demonstrated that $\% \mathrm{C}_{37: 4}$ has the potential of a quantitative sea ice proxy. Differentiating alkenone contribution from different producers through alkenone profile and DNA data provides crucial information in reconstructing changes in sea surface salinity and sea ice in the past, as well as better evaluate bias in sea surface temperature reconstructions. 